\title{
Juventude, Território, Psicologia e Política: Intervenções e Práticas Possíveis
}

\section{Youth, Territory, Psychology And Policies:} Possible Interventions And Practices

Juventud, Territorio, Psicología Y Política: Intervenciones Y Prácticas Posibles

Ana Chacel de Castro

Pedro Paulo Gastalho de Bicalho

Universidade Federal do Rio de

Janeiro
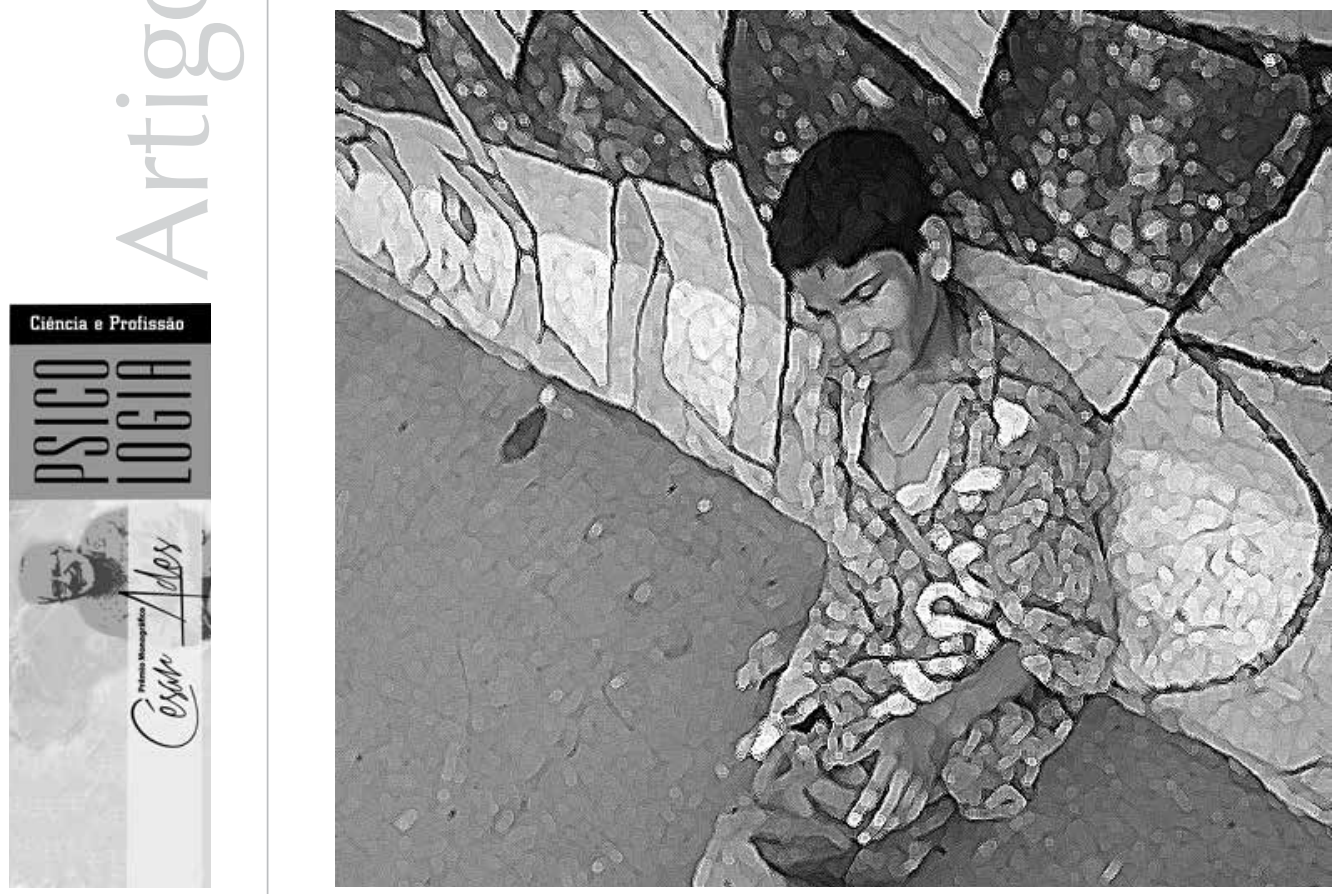
Resumo: O presente trabalho surge do projeto de pesquisa-intervenção Construindo um Processo de Escolhas mesmo Quando Escolher não É um Verbo Disponível, vinculado ao Instituto de Psicologia da UFRJ, e procura colocar em análise as diferentes forças que constituem o processo de produção de subjetividade das juventudes na favela. Através da proposta da prática de análise do vocacional com jovens da favela da Maré, buscou-se acompanhar os processos de escolha que emergem no momento da saída do ensino fundamental e verificar como as perspectivas de futuro podem ser (re)experimentadas no plano de uma coletividade ético-política.

Palavras-chave: Adolescentes. Escolha profissional. Comportamento de escolha. Áreas de pobreza.

\begin{abstract}
This paper is based on the intervention project called "Building a process of choices even when choosing is not an available verb", linked to the Institute of Psychology at UFRJ, and it seeks to analyze the different forces that constitute the process of production of subjectivity of youths in the slum. Through the practice vocational analysis with young people from favela da Maré, we sought to monitor the processes of choice that emerge when they finish elementary school, and how the prospects for the future of these youths can be (re) experienced in terms of an ethical-political community.
\end{abstract}

Keywords: Adolescents. Occupational choice. Institutional analysis. Choice behavior. Poverty areas.

Resúmen: El presente trabajo surge del proyecto de estudio-intervención Construyendo un Proceso de Elecciones incluso Cuando Elegir no Es un Verbo Disponible, vinculado al Instituto de Psicología de UFRJ, y busca colocar en análisis las diferentes fuerzas que constituyen el proceso de producción de subjetividad de las juventudes en las favelas. A través de la propuesta de la práctica de análisis de lo vocacional con jóvenes de la favela de la Maré, se buscó acompañar los procesos de elección que emergen en el momento de la salida de la enseñanza fundamental y verificar como las perspectivas de futuro pueden ser (re)experimentadas en el plan de una colectividad ético-política.

Palabras clave: Adolescentes. Escogimiento profisional. Política. Análisis institucional. Conducta de elección. Areas de pobreza.

Os projetos educacionais comunitários - uma proposta educacional que não se coloca na mesma lógica da escola - aparecem em espaços de socioexclusão (Haesbaert, 2007) onde o acesso a um ensino público de qualidade é precário ou quase inexistente. É justamente esta a proposta de tais projetos: preencher a lacuna educacional, promover condições de igualdade ao ensino público de qualidade bem como investir em uma formação política emancipatória dos alunos. E é nesse último aspecto - o político - que a Psicologia vem contribuir, a partir da atuação nesses espaços. É importante ressaltar que, quando se trata de política, trata-se igualmente da concepção de que a política é ação e posição subjetiva em relação ao mundo, movimentos esses indissociáveis. Dessa forma, pensar sobre política, Psicologia, território e educação é seguir uma lógica de construção e de transformação da realidade social, a partir da própria posição do sujeito frente à sua vida, frente à suas escolhas e sua realidade.
Assim, o projeto Construindo um Processo de Escolhas, mesmo Quando Escolher não É um Verbo Disponível surge no Instituto de Psicologia da UFRJ, em 2006, a partir de uma demanda da entrada da Psicologia em um projeto de extensão de pré-vestibular comunitário (na comunidade do Caju) da própria universidade. Surge então a prática da análise do vocacional (AV), que utiliza o grupo como dispositivo de intervenção. Essa prática considera a escolha profissional um disparador para colocar em análise os processos de escolha e seus efeitos, bem como a construção das trajetórias profissionais e as implicações de cada um nessa construção. Dessa maneira, ao entrarmos no Curso Preparatório do Centro de Estudos e Ações Solidárias da Maré (CEASM), convocamos os alunos de tal curso, participantes da intervenção da Psicologia, para avaliar e construir essa trajetória não natural dos moradores de comunidades. $\mathrm{E}$ por que o acesso a um ensino público de qualidade, como universidades públicas ou escolas técnicas federais, é uma trajetória 
não natural aos moradores de comunidades? Pensando na realidade socioeducacional em que esses moradores estão inseridos, é possível esboçar as oportunidades de trabalho e a construção subjetiva de existência que colocam o morador da favela com pouco acesso às escolas de qualidade e que abarcam a noção de que favelado é alguém por si só desqualificado e marginalizado. A partir desse cenário pré-conceituado e pré-fabricado, nós questionamos então que trajetória (profissional e pessoal) é destinada a uma juventude moradora de favela? A trajetória de pedreiro, de eletricista, de doméstica, de traficante... trajetórias naturais para um favelado, que afirmam e potencializam noções subjetivas e quase sempre sociais de desqualificação e de marginalização dos jovens moradores da favela (Coimbra, 1998). Dessa forma, para tal juventude, o desejo de entrar em uma instituição de ensino de qualidade torna-se uma problemática, uma luta, até mesmo uma subversão do seu papel perante a sociedade civil.

Nesse sentido, a prática da análise do vocacional (AV) pretende, junto aos alunos do Curso Preparatório do CEASM, trabalhar as escolhas que são feitas ao longo da vida. Partindo da opção profissional, vamos construindo as escolhas nos mais diversos âmbitos da vida de cada um, entendendo essa escolha como um processo, e não somente como uma tomada de decisão. Assim, os encontros em grupo permitem a construção de uma noção histórica, social e pessoal das escolhas, fazendo com que os participantes dessa intervenção percebam que existem critérios e vínculos que nos fazem optar por uma coisa ou por outra. Como uma atuação política da Psicologia, a prática da AV não vai apenas considerar a noção da escolha como processo, mas também convocará cada um dos participantes de tal intervenção a pensar, a construir e a responsabilizar-se por tais processos de escolha, processos esses que, entendidos justamente como históricos, se constituem em bifurcações, desvios e ações críticas; assim, constroem-se de forma singular, permeados pela história de cada um, e não pelo estereótipo que lhes é designado. Dessa forma, podemos refletir que, ao construir seus próprios processos de escolhas, as juventudes da favela vão também construindo seus próprios processos de singularização, sendo esta uma afirmação da autonomia e da convocação daqueles alunos para serem atores e construtores da sua realidade e de seu entorno. É a afirmação da micropolítica como forma de atuação no mundo para a transformação social, para além de políticas públicas massificantes e cristalizadas (Monteiro, Coimbra, \& Mendonça Filho, 2006).

\section{Juventudes criminalizadas: uma produção capitalística}

O encontro da Psicologia com a juventude da favela e suas escolhas implica não só a análise da própria intervenção psicológica como também um entendimento da produção do processo de criminalização dessa juventude. Pensar sobre a subjetividade como produção histórico-social, portanto, se faz necessário para o entendimento da construção subjetiva da juventude da favela.

A noção moderna de sujeito apreende uma natureza ou essência, definida a partir de determinantes universais dados a priori. De encontro a essa composição, está o conceito de produção de subjetividade, segundo Guattari e Rolnik (2010), que descreve essa natureza como industrializada. Trata-se de entender a subjetividade como o entrecruzamento de forças múltiplas, de atravessamentos que compõem e que configuram, a cada encontro, uma nova multiplicidade, de forma que a identidade dá lugar ao heterogenético, ao movimento e ao processual. A subjetividade, portanto, não apenas é produzida pelos diversos agenciamentos que a compõem no 
movimento histórico-social mas também se constitui a partir de seus territórios e movimentos. Assim, a produção de subjetividade, como efeito de relação de forças, implica novas composições, afirmando um caráter processual, histórico e mutável das formas de viver o mundo.

Guattari e Rolnik trazem a concepção de subjetividade atrelada ao conceito de economia subjetiva capitalística. As forças que produzem sujeitos não incidem de maneira centralizada no indivíduo, mas dizem respeito a uma espécie de economia coletiva, como um maquinário de expressão que produz vetores subjetivos em larga escala: são forças hegemônicas que atravessam a produção de subjetividade de maneira também hegemônica. Incidindo em todos os níveis de produção e de consumo, essa economia se traduz na tendência de igualar tudo e todos a uma imagem de referência, daí a noção de subjetividade serializada, industrializada e nivelada em escala mundial. Configurase, assim, o capitalismo mundial integrado, que, segundo o autor, se sustenta a partir de três principais tecnologias: a culpabilização, a infantilização e a segregação, esta última um processo de construção da hierarquia inconsciente do âmbito social, ou seja, a criação de um campo de valorização social, no qual cada pessoa deve enquadrar-se em um determinado e exclusivo lugar das diferentes camadas e papéis. Para Guattari e Rolnik, a ordem capitalística "advém nos esquemas de conduta, de ação, de gestos, de pensamento, de sentido, de sentimento, de afeto, etc." (Guattari \& Rolnik, 2010, p.51).

Em outras palavras, o modo de produção dessa economia incide não apenas no plano econômico e social, dos bens e das relações sociais, mas na própria produção de subjetividade, constituindo padrões de sentimentos e relações que são forjados por certas práticas histórico-sociais. Em consequência, entende-se também que tais práticas engendram nesse mundo sentimentos e identidades sociais diversas, moldando diferentes rostos, diferentes fisionomias para o medo, a insegurança, o amor e o ódio (Coimbra, 1998). Foucault (como citado em Coimbra, 2006) nos aponta o dispositivo de periculosidade como aquele que permite a emergência dos "inimigos da sociedade". Esse dispositivo, que é formado por tais práticas e discursos sociais mencionadas acima, vai afirmar que mais importante que o ato individual é o que o indivíduo em si poderá vir a fazer: o controle das virtualidades. Existirão, portanto, certas naturezas (como ser pobre, negro, semialfabetizado, etc.) em que o ato perigoso lhes será intrínseco, e, a qualquer momento, poderá fazê-los entrar no caminho da criminalidade. Nesse sentido, há uma modelização, a cada momento histórico, das classes perigosas em potencial, constituídas por sujeitos que devem ser evitados e excluídos para o melhor desenvolvimento da sociedade - é a construção do processo de criminalização de um segmento da população.

Atualmente, aqueles que experimentam tal papel são os segmentos mais miseráveis, mais pauperizados, como os moradores de favela: aqueles que os discursos e práticas sociais consideram suspeitos, perigosos. Assim, podemos considerar que os pobres, antes mesmo de nascer, por suas virtualidades de periculosidade, têm suas identidades forjadas, e suas "... formas de sentir, viver e agir são tornadas homogêneas, percebidas como inferiores, e por isso, desqualificadas. São, por exemplo, crianças e adolescentes já na marginalidade ou que poderão se tornar marginais - porque pobres" (Coimbra, 1998, p. 6).

É, portanto, a partir dessa economia subjetiva capitalística que a produção subjetiva da juventude moradora da favela se vê fortemente atravessada pelo vetor da pobreza e, por conseguinte, produzida pelo processo 
de segregação. É como nos diz Forrester:

Para esses 'jovens' (do subúrbio sensível), destinados de antemão a esse problema, fundidos com ele, o desastre é sem saída, e sem limites, nem mesmo ilusórios. (...) Marginais pela sua condição, geograficamente definidos antes mesmo de nascer, reprovados de imediatos, eles são os 'excluídos' por excelência. (1997, p. 58)

Contudo, como entender melhor a configuração e a emergência de tais subjetividades da juventude? Como perceber que linhas são delineadas e traçam a produção de subjetividade na favela? Que vetores de forças se entrecruzam e se atravessam nessa emergência? E, acima de tudo: como, diante de uma produção serializada da individualização (assegurada pelas três tecnologias citadas anteriormente), podemos criar novas formas de diferenciação de ser, em que a singularização, os desvios, as rupturas e a criação possam emergir como novos processos de produção? Para além do processo de criminalização que atravessa a juventude da favela, é preciso, então, atentar que o próprio território favela se constitui como agenciamento para subjetividades marginalizadas.

\section{Favela: um território ausente}

A construção e o estabelecimento de um território espacial é também a construção contínua de uma rede de vetores informacionais, tecnológicos, históricos e sociais. É através dessa construção territorial que se dá no espaço que podemos também pensar na produção de subjetividade que emerge no processo social de território e de rede. No contexto atual da globalização, há determinados territórios que se constituem pela noção de ausência: as favelas. Tais espaços são definidos predominantemente pelo que não têm ou pelo que não são (Silva, 2007).
Assim sendo, o território espacial da favela não apenas é destituído de infraestrutura necessária mas também da própria constituição subjetiva de cidadania, pois seu desordenamento e sua carência de serviços essenciais possibilitam a emergência de um território que, como nos diz Haesbaert (2007), é primordialmente desterritorializado, ou seja, é um território onde existe um processo de exclusão socioespacial.

Tal exclusão tem início em fins do século XIX, quando o paradigma higienista incide em propostas políticas e projetos urbanísticos de reordenamento da cidade. Com a construção de vias largas, destinadas à velocidade e não mais às pessoas e aos seus encontros, as cidades e suas ruas reformadas tornamse espaços apenas de circulação e de consumo. Partindo da ideia higienista de um corpo asséptico, saudável e disciplinado, o desenho urbano das cidades passa a funcionar da mesma maneira. Assim, populações miseráveis moradoras da cidade, por seu caráter perigoso e sujo, são compulsoriamente deslocadas e excluídas para outros territórios (as encostas dos morros, que, posteriormente, serão denominadas favelas) que são excluídos da cidade limpa e reordenada (Coimbra, 2006).

Essa exclusão, portanto, que ocorre por fronteiras urbanísticas concretas, faz do território da favela um lugar de construção subjetiva marginalizada. Sendo contraposta por um determinado ideal de urbano, a favela é vista como um espaço externo à polis - o território delineado, por excelência, como o lugar de exercício da cidadania. A subjetividade, portanto, produzida, construída e constituída no espaço da favela, carrega consigo o processo de segregação trazido pelo território que a atravessa. Dessa forma, quando pensamos na emergência territorial de espaços segregados e marginalizados, como é o que ocorre com os espaços favelados, as subjetividades ali também são 
O cartógrafo, então, ao habitar e produzir um campo, passa também a engendrar as potentes e diferentes possibilidades de vida, fazendo da pesquisa um ato político, produtor de sociedades e criador de mundos (Rolnik 1989). produzidas pela noção de ausência que seus territórios contém, ausência essa que, para autores como Silva, apenas reafirma a condição de exclusão e de marginalização dos moradores da favela:

A vivência em um território restrito, sem parâmetros mais abrangentes de circulação na cidade, contribui para que o lugar seja o ponto de partida e de chegada da existência. Morador de favela, o agente não se reconhece, muitas vezes, como cidadão pertencente à polis, à cidade.

(2007, p. 228)

\section{Processos de escolha e a pesquisa-intervenção}

O projeto de pesquisa-intervenção Construindo um Processo de Escolhas mesmo Quando Escolher não É um Verbo Disponível, ponto de partida do presente artigo, centraliza sua discussão na produção de subjetividade da juventude da favela e nos seus processos de escolha. Portanto, é a partir dessas perspectivas que apontamos a prática da análise do vocacional como um dispositivo de análise da juventude e também como dispositivo político de transformação social.

Assim sendo, a prática de uma pesquisa que pretende não só uma análise do objeto investigado mas também uma invenção de novos processos para esse objeto necessita pensar em ferramentas que levem em consideração a produção de mundos (e de conhecimento), pensar em uma pesquisa em que se permita a criação no entre, no processo: uma pesquisa-intervenção. Para tanto, o modelo de pesquisa-intervenção utiliza o método da cartografia, em que o objeto investigado é um objeto não representável - tal metodologia vê este último como um fluxo, um devir (Passos, Kastrup, \& Escóssia, 2010). Nesse sentido, é premissa do cartógrafo não mais referir-se à aplicação do saber para conhecer a realidade, mas o de conhecer fazendo:
Conhecer a realidade é acompanhar seu processo de constituição, o que não pode se realizar sem uma imersão no plano da experiência. Conhecer o caminho de constituição de dado objeto equivale a caminhar com esse objeto, constituir esse próprio caminho, constituir-se no caminho .(Passos et al., 2010 p.31)

A pesquisa-intervenção, portanto, consiste em acompanhar os processos que se dão no plano das experimentações, sendo esse um plano de produção do campo, do investigador, da prática e da teoria. Nesse sentido, a cartografia subverte a lógica metodológica que possui regras previamente estabelecidas, e vai incorporar procedimentos mais abertos e inventivos, construindo e constituindo-se no mesmo processo de investigação do campo: não são mais as metas pré-fixadas que traçam o caminho - "do metá-hódos...", mas é no próprio percurso que elas são traçadas - “... ao hódos-metá" (Passos et al., 2010).

Assim, o pesquisador (ou o cartógrafo) não é indissociado do objeto que pesquisa e do conhecimento que produz, mas cria-se também no processo da pesquisa, já que ela é, em última instância, uma análise cunhada no desejo (Rolnik, 1989). O papel do cartógrafo passa a ser o de justamente traçar as estratégias de formação do desejo, de perscrutar tudo que dá vasão aos movimentos do desejo, que serve para entender a matéria de expressão e de criação das escolhas. O cartógrafo, então, ao habitar e produzir um campo, passa também a engendrar as potentes e diferentes possibilidades de vida, fazendo da pesquisa um ato político, produtor de sociedades e criador de mundos (Rolnik, 1989).

Ao entender nosso campo habitado pela juventude da favela, pode-se questionar como é possível acompanhar os processos de construção de escolhas dessa juventude e, por conseguinte, da sua tentativa de construir uma 
autonomia em detrimento de todo processo de criminalização por qual ela passa. Para isso, é necessário avaliar, primeiramente, como as escolhas se constituem no mundo contemporâneo.

Para Maciel Jr. (2005) a criação de escolhas no contexto da contemporaneidade é cada vez mais tratada como algo impossível, já que impera uma imposição de escolhas pré-fabricadas pelo campo sociopolítico, controladas por mecanismos de poder que se exercem sobre nossa subjetividade e nossas condições de viver. É o que Foucault (como citado em Maciel Jr.) chamou de biopoder:

As dimensões (da vida) que até então eram consideradas íntimas, aquelas que se referiam à escolha privada dos indivíduos, têm agora o seu campo de possíveis explicitado e gerido, desaparecendo a distinção entre vida privada e pública, e mesmo entre a vida subjetiva e o simples viver. (2005, p. 52)

É dessa forma que pensamos, ao escolher o pai de uma criança, uma sexualidade alternativa ou uma profissão específica, estar escolhendo de forma exclusiva, quando, na verdade, essas possibilidades já chegam a nós produzidas e controladas. As escolhas, portanto, são geridas por um campo de decisões previamente estabelecido, determinado culturalmente, integrando funções políticas que ordenam, normatizam e produzem subjetividades e comportamentos. Em consequência, as relações que estabelecemos com a família, com a escola, com o bairro e com os amigos passam também pela condição de alternativas determinadas: pela nossa condição financeira, pela nossa história, pela nossa geografia, pela nossa política e nossa governamentabilidade. Assim, para Foucault (como citado em Maciel Jr., 2005), os saberes integradores das funções políticas são aqueles que criam o campo de expectativas possíveis de um indivíduo, este também produzido nos dispositivos que instituem tais saberes. Trata- se, portanto, de dispositivos de saber-poder, cujas relações estabelecem um exercício de forças e que têm como função ordenar e produzir afetos que se integrarão em comportamentos devidamente normatizados. Entendendo que as alternativas de escolha são produzidas a partir desses dispositivos, podemos, portanto, pensar que as próprias escolhas são impostas por um campo de possíveis já determinado.

Se isso acontece, como fazer uma escolha que perpasse esse campo, transborde os limites conformados e crie novas configurações subjetivas? É nesse sentido que a prática da análise do vocacional surge como intervenção da pesquisa junto aos jovens moradores da favela da Maré, alunos do Curso Preparatório para Escolas Técnicas Federais do Centro de Estudos Ações Solidárias da Maré (CEASM). A prática, feita em grupo (com média de 15 a 20 participantes), ocorre em três etapas: primeiramente, inicia-se a intervenção com uma entrevista individual, utilizada para levantamento de demandas e questões. Ocorrem, em seguida, dez a doze encontros em grupo, nos quais, através de dispositivos como dinâmicas, textos e o próprio grupo, é realizado o exercício da problematização dos processos de escolha dos participantes. Ao fim, é elaborado um laudo psicológico individual (conforme a Resolução $\mathrm{n}$ 은 007/2003, do CFP) de cada um dos participantes e feita uma entrevista devolutiva com a entrega do documento, entendendo-o como um dispositivo potente para a reflexão sobre o processo de singularização que cada participante experimentou ao longo do trabalho. É importante ressaltar que o grupo, como dispositivo, permite a experiência de determinadas situações cotidianas de maneira inventiva, em que o entrecruzamento de olhares sobre a mesma questão pode provocar desestabilizações e produções de novos modos de ser (Frotté, 2001). 
Pode-se dizer que o campo das escolhas da juventude da favela se torna também um campo de produção de subjetividades e de linhas de fuga, provocando a ruptura de cristalizações e de naturalizações acerca do entendimento das condições e das possibilidades de vida do pobre e do favelado.

Se, para Maciel Jr., nossa condição de escolher está atrelada à noção de um futuro "como um projeto que venha garantir a melhoria ou continuidade de uma maneira de ser estabelecida culturalmente" (2005, p. 54), e que essa maneira de ser é identificada com os processos de consumo e de uma vida qualitativamente (e quantitativamente, por que não dizer?) controlável, existe uma parcela da população à qual essa condição de escolha não é oferecida - ou, se oferecida, é de forma ainda mais delimitada e controlada: a população pobre, moradora da favela. Para Forrester, a juventude moradora de bairros difíceis, por sua condição primeira de não acesso às possibilidades, sofre de antemão de um vazio perante o futuro: "O vazio e a ausência de qualquer projeto, de qualquer futuro, de qualquer felicidade ao menos visualizada, de qualquer esperança..." (1997, p. 73).

É possível, então, notar que a naturalização de uma juventude da favela que não tem futuro é delineada, afirmada e construída por diversos vetores que compõem o território geográfico e subjetivo da juventude da favela: as fronteiras espaciais que não podem ser ultrapassadas por esses jovens compartilhamos a televisão e a publicidade, mas jamais nossos ambientes de lazer, de aprendizado e de produção de si mesmo; a ausência de escolas de qualidade no entorno geográfico dessa juventude; as políticas públicas de governo, que têm como principal forma de intervenção com esses jovens a ação policial opressora, todos esses vetores configuram e acabam por produzir, na semiótica da pobreza, identidades homogêneas, inferiores e desqualificadas (Coimbra, 1998). Há, portanto, no território da favela, a emergência de uma juventude sem saída.

A partir disso, a prática da análise do vocacional, inserida no curso preparatório, pretendeu trabalhar as escolhas desses jovens, moradores da favela da Maré, um contexto psicossocial em que só a possibilidade de estar em um curso preparatório se mostra como uma oportunidade de ampliar o horizonte educacional, profissional e pessoal.

Como, então, pensar sobre as escolhas de uma juventude previamente atravessada e constituída por uma política governamental que já as considera fora de uma perspectiva de emprego, de inteligência, de normalidade? O que pensar de uma escolha, quando esta não segue o seu caminho natural? O que é lutar por uma escolha diferente, quando esta é simplesmente uma educação de qualidade e continuada?

\section{Pensando sobre a prática...}

A prática da análise do vocacional (AV), como proposta de intervenção e de atuação de uma psicologia política, possibilita a problematização de discursos e práticas que estão em jogo na emergência das subjetividades dessa juventude da favela. Assim sendo, ao longo dos encontros no primeiro semestre de 2012, buscou-se, a cada temática e a cada questionamento coletivo levantado, problematizar as escolhas pré-fabricadas, afirmando a possibilidade de construção e de processualidade de tais escolhas, entendendo-as como atravessamento na produção da nossa própria subjetividade.

Nos encontros realizados durante o semestre, pôde-se perceber que alguns relatos emergiram como indicadores da posição subjetiva na qual esses jovens se encontram 
como atores sociais: em uma discussão sobre o tema da liberdade, um dos alunos ponderou que "não tem liberdade quando há falta de dinheiro... é, porque na favela, não se vive liberdade"; já quando abordamos a possibilidade de eles se manterem em uma escola do ensino médio dentro da favela, outro adolescente reclamou que "na escola da favela, a pessoa entra burro e sai retardado"; ou quando falamos sobre a própria condição de ser favelado, uma das alunas comentou que "as pessoas têm preconceito com favelado... às vezes parece que sou lixo". Observações como essas nos trazem a noção de que a segregação e a pobreza constituem vetores que atravessam e constroem a subjetividade desses jovens, delineando sua condição psicossocial como lixo, burro e sem liberdade. Ora, se a emergência subjetiva de tal juventude se dá pelo contexto de um processo de criminalização, como considerar as possibilidades de escolha que aparecem para ela?

Diante de tal cenário, em que a subjetividade se produz como impotência, e não o contrário, a intervenção da AV aposta na construção de um processo de escolhas, em que este possa ser entendido, em última instância, como uma escolha da escolha - a partir da metodologia apresentada, tentamos provocar cada um dos participantes a engendrar potentes e diferentes possibilidades de vida. Mapeando o processo de formação das escolhas que emergem pré-fabricadas, acompanhamos e elaboramos as relações de poder que as atravessam e as moldam, e assim, convocamos os sujeitos da nossa pesquisa (e intervenção) a tomar uma decisão sobre suas escolhas, e a poder, de modo conciso, determinar uma (re)invenção de si mesmos e do mundo (Passos et al., 2010).

Dessa forma, ao longo processo do grupo, os alunos do curso preparatório puderam afetarse pelos estranhamentos das naturalizações experimentadas até então, e puderam provocar bifurcações e linhas de fuga na sua produção subjetiva. Novos relatos emergiram como a potência de outras possibilidades de ser, entendendo eles também que as escolhas permeiam essas novas invenções (de si mesmos e do mundo): sobre ser favelado, estigma que muitas vezes pesa para aqueles que ali moram, um dos alunos reavalia tal conceito, dizendo que "tem aquele favelado que não quer nada com a vida e tem gente como nós"; já no encontro em que propusemos a construção do constructo liberdade, um dos alunos concluiu que "liberdade é fazer as escolhas certas com a consciência limpa", e a própria noção da escolha foi desconstruída e (re)visitada, no momento em que uma das alunas nos fala sobre o caráter processual nela incluído, em que pode ser engendrada e construída no caminho que percorremos, trazendo a noção de que "as escolhas que fazemos no caminho fazem diferença. Se eu venho para o CEASM, mas escolho não estudar, não adianta nada!"

Assim, ao abordar o processo de segregação e de exclusão vivenciado pelo jovem morador de favela de maneira inventiva e aberta, é possivel também acompanhar e participar de seus processos de criação e de composição de redes de atravessamentos que constituem e transformam, a cada instante, o sujeito e suas escolhas. A produção que emerge não é simplesmente a identificação e a circunscrição das subjetividades que se configuram no contexto da favela, mas sim, a emergência de processos subjetivos que escapam a essa identidade-referência e que criam novas possibilidades de ser. São processos de singularização (Guattari \& Rolnik, 2010) em que as raízes produtivas da singularidade emergem como plural, como novos vetores de se viver o desejo.

\section{Reverberações do processo para o campo político}

Pensando sobre a prática da análise do 
Segundo Monteiro et al., na contemporaneidade, existe a produção do mito de um Estado Democrático de Direito, o qual tem associadas as noções de público e de comum.

Contudo, como a lógica de poder regente se dá pelo biopoder, a produção e a transformação da vida ocorrem na própria imanência do capital. vocacional como prática psicológica éticopolítica, essa vertente aposta no fato de que os participantes do grupo podem construir, eles próprios, linhas de fuga, enfrentar os impasses que surgirem e inventar saídas para novas possibilidades. É a produção desses novos modos de pensar, de perceber, de sentir e de agir que fazem da atuação de uma prática, uma micropolítica, que reverbera de maneira muitas vezes mais intensa que as chamadas políticas públicas.

Segundo Monteiro et al., na contemporaneidade, existe a produção do mito de um Estado Democrático de Direito, o qual tem associadas as noções de público e de comum. Contudo, como a lógica de poder regente se dá pelo biopoder, a produção e a transformação da vida ocorrem na própria imanência do capital. O desenvolvimento do capitalismo traz consigo uma transformação do direito político, que passa a ser vivido como uma sociedade pautada na separação daqueles que podem/devem viver para os quais basta deixar morrer. Assim, na atual sociedade globalizada, o consumo e a ascensão social tornam-se pré-requisitos de humanidade. Nesse contexto, Monteiro et al. trazem a ideia, portanto, da impossibilidade de uma democracia (e do entendimento do público pela mesma) quando esta se encontra com práticas de resignação frente a tal lógica de poder. Para os autores, público não está conectado à noção de um plano comum, ou do Homem Idealizado, de direitos idealizados. Monteiro et al. afirmam que “... o público diz respeito à experiência concreta dos coletivos de forças sempre movimento" (2006, p. 11), diz respeito também às práticas que engendram novos modos de subjetivação, de (re)invenção de si mesmo e do mundo.

Entender a prática psicológica como aposta da criação de processos de singularização é também entender tal prática como uma micropolítica pública, construída na experiência concreta de novas invenções subjetivas, ao contrário de políticas públicas que se pautam no caráter de Estado democrático definitivo e cristalizado, que massifica e serializa os modos de ser (Monteiro et al., 2006).

\section{Considerações finais}

O presente trabalho, ao propor a problemática de um campo como movimento, como transformação, traz-nos uma invenção histórica e territorial da subjetividade que, quando atravessada pela semiótica da pobreza e da favela, é produzida no âmbito da marginalização e da criminalização.

Portanto, a habitação de um campo atravessado por estigmas e criminalizações poderia apenas mostrar-nos uma paralisação da vida que ali existe. Contudo, justamente pela possibilidade de habitar e de experimentar tal campo é que o movimento se fez imprescindível, se fez efeito e transformação. As subjetividades que ali se inventaram, afetadas pelo encontro com a intervenção, afirmaram novas possibilidades de ser, novas possibilidades de mover, criaram novos caminhos e outras bifurcações para expressar-se, caminhos para construírem para si mesmos, a cada encontro, novas potencialidades para suas afirmações e escolhas. Foi um processo de constituição de uma micropolítica capaz de transformação social, engendrando bifurcações para experiências de invenção de si mesmo que não constituídas pela lógica capitalística vigente, um processo de construção de atores sociais e implicados em seu contexto.

Assim, para a juventude da favela, que de antemão se vê com suas alternativas limitadas, a possibilidade de um encontro com tal espaço de intervenção mostrou-se também como a possibilidade de um encontro político e de cidadania, no qual os efeitos podem reverberar para além do seu próprio território, com novas configurações subjetivas e novos espaços ético-políticos. 
Se, por um lado, a pobreza e o território geográfico da favela levaram à produção de subjetividades marginalizadas e desqualificadas, a des-re-territorilização de tais processos (seja do próprio território, seja da subjetividade) provocou novas invenções e percepções sobre a favela e o ser favelado, criando territórios plurais, coletivos e, ainda sim, singulares. Como nos aponta Martins e Ribeiro, "possibilitar o novo e a compreensão da multiplicidade inerente ao ser, ativo, na construção desse espaço, é ferramenta política, é assim, território e territorialidade, a propulsionar multiterritorialidades" (2011, p.24).

Ana Chacel de Castro

Discente do curso de Psicologia da Universidade Federal do Rio de Janeiro, Rio de Janeiro - RJ - Brasil.

E-mail: ana_chacel@hotmail.com

Pedro Paulo Gastalho de Bicalho

Doutor em Psicologia pela Universidade Federal do Rio de Janeiro e docente do Programa de Pós-Graduação em Psicologia da Universidade Federal do Rio de Janeiro, Rio de Janeiro - RJ - Brasil.

E-mail: ppbicalho@gmail.com

Endereço para envio de correspondência:

Rua Senador Vergueiro, 30/90, Flamengo. CEP: 22230-00. Rio de Janeiro, RJ. 
Coimbra, C. B. (1998). Produção do medo e da insegurança. (Texto do Banco de Produção Docente do Programa de Pós-graduação de Psicologia da Universidade Federal Fluminense). Niterói, RJ: UFF. Recuperado em 22 de junho, 2013 de http://server.slab.uff.br/textos/texto64.pdf

Coimbra, C. B. (2006). Direitos humanos e criminalização da pobreza. (Texto do Banco de Produção Docente do Programa de Pós-Graduação de Psicologia da Universidade Federal Fluminense). Niterói, RJ: UFF. Recuperado em 22 de junho, 2013 de http://server.slab.uff.br/textos/texto54.pdf

Forrester, V. (1997). O horror econômico. São Paulo: Unifesp.

Frotté, M. D. (2001). Analítica do vocacional: percursos e derivas de uma intervenção. (Dissertação de Mestrado). Instituto de Psicologia, Universidade Federal Fluminense, Niterói, RJ.

Guattari, F., \& Rolnik, S. (2010). Micropolítica: cartografias do desejo. Petrópolis, RJ: Vozes.

Haesbaert, R. (2007). Concepções de território para entender a desterritorialização. In M. Santos \& B. K. Becker. (Orgs.), Território, territórios: ensaios sobre o ordenamento territorial (pp. 43-71). Rio de Janeiro: Lamparina.
Maciel Júnior, A. (2005). O problema da escolha e os impasses da clínica na era do biopoder. In A. Maciel Júnior, D. Kupermann \& S. Tedesco. (Orgs.), Polifonias: clínica, política e criação. Rio de Janeiro: Contracapa.

Martins, I. M. M., \& Ribeiro, M. A. (2011). Liberdade e desejo na construção de identidades: múltiplos espaços, múltiplos migrantes. Tempo, Espaço e Linguagem, 2(2), 07-25.

Monteiro, A., Coimbra, C., \& Mendonça Filho, M. (2006). Estado democrático de direito e políticas públicas: estatal é necessariamente público? Psicologia e Sociedade, 18(2), 7-12. doi: http://dx.doi.org/10.1590/S0102-71822006000200002

Passos, E., Kastrup, V., \& Escóssia, L. (Orgs.). (2010). Pistas do método da cartografia: pesquisa-intervenção e produção de subjetividade. Porto Alegre: Sulina.

Rolnik, S. (1989). O cartógrafo. In S. Rolnik. Cartografia sentimental: transformações contemporâneas do desejo (pp. 65-72). São Paulo: Estação Liberdade.

Silva, J. S. (2007). Um espaço em busca do seu lugar: as favelas para além dos estereótipos. In M. Santos \& B. K. Becker. (Orgs.), Território, territórios: ensaios sobre o ordenamento territorial (pp. 209-230). Rio de Janeiro: Lamparina. 